November 27, 2015

\title{
Three Easy Pieces
}

\author{
Arne Schön and Ernesto Freire* \\ Department of Biology \\ Johns Hopkins University \\ Baltimore, MD 21218
}

Corresponding author: Freire, E. (ef@jhu.edu).

Supported by grants from the National Science Foundation (MCB0641252) and the National Institutes of Health (GM56550). 


\section{ABSTRACT}

Background: Differential scanning calorimetry is a powerful method that provides a complete thermodynamic characterization of the stability of a protein as a function of temperature. There are, however, circumstances that preclude a complete analysis of DSC data. The most common ones are irreversible denaturation transitions or transitions that take place at temperatures that are beyond the temperature limit of the instrument. Even for a protein that undergoes reversible thermal denaturation, the extrapolation of the thermodynamic data to lower temperatures, usually $25^{\circ} \mathrm{C}$, may become unreliable due to difficulties in the determination of $\Delta C_{p}$.

Methods: The combination of differential scanning calorimetry and isothermal chemical denaturation allows reliable thermodynamic analysis of protein stability under less than ideal conditions.

Results and Conclusions: This paper demonstrates how DSC can be used in combination with chemical denaturation to address three different scenarios: 1) Estimation of an accurate $\Delta C_{p}$ value for a reversible denaturation using as a test system the envelope HIV-1 glycoprotein gp120; 2) Determination of the Gibbs energy of stability in the region in which thermal denaturation is irreversible using HEW lysozyme at different pH values; and, 3) Determination of Gibbs energy of stability for a thermostable protein, thermolysin.

Keywords: DSC, ICD, chemical denaturation, HIV-1 gp120, HEW lysozyme, thermolysin 


\section{INTRODUCTION}

The conformational stability of a protein is dictated by its Gibbs energy, $\Delta G^{\circ}$, which is a function of temperature as well as other physical and chemical conditions. Two techniques allow measurement of $\Delta G^{\circ}$ : 1) Differential scanning Calorimetry (DSC); and, 2) Chemical Denaturation measured at a single temperature (ICD). Differential scanning calorimetry measures the temperature dependence of the heat capacity function of the protein (1-3). Subsequent analysis of the heat capacity function provides a complete thermodynamic description of a transition, the changes in enthalpy, entropy and heat capacity, which allows definition of $\Delta G^{\circ}$ at any temperature $(3,4)$.

There are situations, however, in which the analysis of the heat capacity function becomes extremely difficult or impossible to implement. In this paper we will consider three different conditions and how a combination of DSC and chemical denaturation data can address those difficult situations and provide reliable estimates of $\Delta G^{\circ}$ at different temperatures. The first case to be considered is the situation in which $\Delta C_{p}$ determination is unreliable due to an inaccurate determination of the initial and final baselines (i.e. the heat capacity of the native and denatured states). The second case corresponds to the situation in which the denaturation transition is irreversible. In many cases reversibility is observed at low $\mathrm{pH}$ but the transition becomes irreversible at neutral $\mathrm{pH}$, which which usually is the $\mathrm{pH}$ of interest $(1,5,6)$. The third case corresponds to the situation 
in which the protein is extremely stable and denaturation occurs above the temperature range of the instrument. 


\section{MATERIALS AND METHODS}

\subsection{Reagents}

Lyophylized thermolysin from Bacillus thermoproteolyticus (EC 3.4.24.27) and hen egg white lysozyme (EC 3.2.1.17) were obtained from Sigma-Aldrich (St. Louis, MO, USA) and used without any further purification. Thermolysin was dissolved in $10 \mathrm{mM}$ hepes, $100 \mathrm{mM} \mathrm{NaCl}$ and $10 \mathrm{mM} \mathrm{CaCl}$, $\mathrm{pH}$ 7.5. Lysozyme was prepared in PBS, pH 7.5. The HIV-1 envelope glycoprotein gp120 from the YU2 strain was expressed in human 293F cells and purified by affinity chromatography using the monoclonal antibody $17 \mathrm{~b}$ as described in detail elsewhere (7). gp120 was finally dialyzed against PBS, pH 7.5. Ultrapure urea was from J.T. Baker (Center Valley, PA) and molecular grade $\mathrm{GdnHCl}$ was from Promega Corporation (Madison, WI, USA). PBS was purchased from Roche Diagnostics GmbH (Mannheim, Germany). All other buffer components were from Sigma-Aldrich (St. Louis, MO, USA).

\subsection{Differential Scanning Calorimetry}

Thermal denaturation experiments were performed using a VP-DSC microcalorimeter from MicroCal/Malvern Instruments LLC (Northampton, MA, USA). The protein samples were dialyzed into buffer, concentrated to $\sim 1 \mathrm{mg} / \mathrm{mL}$ and thoroughly degassed before loading of the calorimetric cell $(\sim 0.5 \mathrm{~mL})$. The reference cell was filled with dialysis buffer. The cells were pressurized at $25 \mathrm{psi}$ and all scans were carried out at a rate of $1^{\circ} \mathrm{C} / \mathrm{min}$. The experiments with gp120 
and lysozyme were carried out in PBS, pH 7.5. The experiment with thermolysin was carried out in $10 \mathrm{mM}$ hepes, $100 \mathrm{mM} \mathrm{NaCl}$ and $10 \mathrm{mM} \mathrm{CaCl}_{2}, \mathrm{pH}$ 7.5.

\subsection{Chemical Denaturation Experiments}

All denaturation experiments were carried out using Unchained Labs Hunk Automated Protein Denaturation System with fluorescence detector (Unchained Labs, Norton, MA). The excitation wavelength was $280 \mathrm{~nm}$ and scans of the emission intensity were recorded between 300 and $500 \mathrm{~nm}$. For each denaturation experiment, protein, buffer and denaturant (urea or $\mathrm{GdnHCl}$ ) were dispensed into 36 wells with a linear increase in denaturant concentration. The experiments with gp120 were carried out using $0-5 \mathrm{M}$ urea in PBS, $\mathrm{pH}$ 7.5. The tryptophan emission maximum occurs at $344 \mathrm{~nm}$ for the native state and changes to $356 \mathrm{~nm}$ upon denaturation of gp120, which allows for easy monitoring of the transition. The experiments with lysozyme were performed at $\mathrm{pH} 4.0,5.0$, 6.0, 7.0, and 7.5 using a gradient of $0-6.4 \mathrm{M} \mathrm{GdnHCl}$. Denaturation experiments with lysozyme at $\mathrm{pH} 7.5$ were also performed using a gradient of 0 5.5 M GdnHCl in the presence of 1,2, and $3 \mathrm{M}$ urea. The buffers used were 10 $\mathrm{mM}$ sodium phosphate $(\mathrm{pH} 6.0-7.5), 10 \mathrm{mM}$ sodium acetate $(\mathrm{pH} 5.0)$, and 10 $\mathrm{mM}$ sodium formate ( $\mathrm{pH} 4.0)$. All buffers contained $150 \mathrm{mM} \mathrm{NaCl}$. Because of the very high stability of thermolysin, denaturation gradients of $0-6.4 \mathrm{M} \mathrm{GdnHCl}$ were run in the presence of $2.5,3$, and $3.5 \mathrm{M}$ urea. The buffer used for all experiments with thermolysin was $10 \mathrm{mM}$ hepes, $\mathrm{pH} 7.5$ with $100 \mathrm{mM} \mathrm{NaCl}$ and $10 \mathrm{mM} \mathrm{CaCl}$. The protein concentration in the wells was $30 \mu \mathrm{g} / \mathrm{mL}$ in all 
experiments. To test the reversibility of chemical denaturation, protein was denatured in high concentration denaturant followed by dilution of the denaturant and incubation for different amount of times in order to assess the kinetics of renaturation. The experimental protocol provided with the instrument allowed for the measurement of full renaturation curves as a function of the incubation time. The protocol was implemented as follows: HEW lysozyme was prepared in a denaturing solution of $5 \mathrm{M}$ GdnHCl plus $2 \mathrm{M}$ urea and diluted 12.5 times into a 36 point linear gradient between 0.4 and $5.9 \mathrm{M} \mathrm{GdnHCl}$ and constant $2 \mathrm{M}$ urea. Thermolysin was prepared in a denaturing solution of $6 \mathrm{M} \mathrm{GdnHCl}$ plus $3 \mathrm{M}$ urea and diluted 12.5 times into a 36 point linear gradient between 0.48 and $6.88 \mathrm{M}$ $\mathrm{GdnHCl}$ gradient and constant $3 \mathrm{M}$ urea. Renaturation of lysozyme was complete within two hours. Renaturation of thermolysin was slower and was measured 11, 16, 24 and 48 hours after dilution from high denaturant concentrations. All measurements including incubation of samples were carried out at $25^{\circ} \mathrm{C}$. Chemical denaturation as a technique to measure protein stability has been around for many years. Reference (8) provide protocols to implement the technique manually. 


\section{RESULTS}

\subsection{Case 1: Thermodynamic Analysis when $\Delta C_{p}$ Determination is}

Unreliable. The thermal denaturation of the HIV-1 envelope glycoprotein gp120 from the YU2 strain is reversible at neutral pH. gp120 is a glycosylated protein with a molecular weight of more than $100 \mathrm{kDa}$ of which more than $50 \%$ corresponds to carbohydrate residues. Previous studies have shown that unliganded gp120 undergoes reversible thermal denaturation in PBS at pH 7.5 (9). Figure 1 shows the heat capacity function of gp120 in PBS at pH 7.5. The DSC trace is characterized by a native state baseline with a pronounced positive slope whereas the denatured baseline is almost devoid of a temperature dependence. This situation has been observed with different proteins (10-12) and precludes a meaningful thermodynamic analysis since a simple extrapolation as shown in the figure will produce a divergent $\Delta C_{p}$ value at low temperatures and consequently unrealistic $\Delta H^{\circ}, \Delta S^{\circ}$ and $\Delta G^{\circ}$ values at low temperatures. In situations like this, only the values for $T_{m}\left(60.8 \pm 0.1^{\circ} \mathrm{C}\right)$ and $\Delta H^{\circ}$ at $T_{m}(130 \pm 10$ $\mathrm{kcal} / \mathrm{mol}$ ) can be determined with sufficient accuracy since they are largely independent of an extrapolated $\Delta C_{p}$ value.

For situations like those in Figure 1, a precise thermodynamic description of the transition can be obtained by combining the DSC data with ICD data. Chemical denaturation experiments for gp120 were performed at $25{ }^{\circ} \mathrm{C}$ using urea as denaturant. Figure 2 shows triplicate measurements of the chemical 
denaturation of gp 120 at $25^{\circ} \mathrm{C}$. The denaturation of gp120 has a midpoint at 2.7 $\mathrm{M}$ urea and is characterized by $\Delta G^{\circ}$ and $m$ values of $7.3 \mathrm{kcal} / \mathrm{mol}$ and 2.7 $\mathrm{kcal} /(\mathrm{mol} \times \mathrm{M})$ respectively. The $m$-value is equal to the rate of decrease of $\Delta G$ with increasing denaturant concentration $\left(\Delta G=\Delta G^{\circ}-m[\right.$ denaturant $]$ ). In addition, the magnitude of $m$ has been shown to be correlated with the change in solvent accessible surface area during denaturation and therefore also with $\Delta C_{p}$ (13).

Chemical denaturation measurements provide directly the value for $\Delta G^{\circ}$ at $25^{\circ} \mathrm{C}$. Using the standard equation for $\Delta G^{\circ}$, this value can be combined with the values for $\Delta H_{T m}^{o}$ and $T_{m}$ obtained by DSC and derive the following equation for $\Delta C_{p}$ :

$$
\Delta C_{p}=\frac{\Delta G_{298.15}^{o}+\Delta H_{T m}^{O} \times\left(\frac{298.15}{T_{m}}-1\right)}{298.15-T_{m}-298.15 \times \ln \left(\frac{298.15}{T_{m}}\right)}
$$

According to the above equation, the $\Delta C_{p}$ value of gp120 equals $3.4 \mathrm{kcal} /(\mathrm{K} \times$ mol). This $\Delta C_{p}$ value can be used to develop a full thermodynamic description of the transition. Figure 3 shows the resulting plot of $\Delta G^{\circ}, \Delta H^{\circ}$ and $-T \Delta S^{\circ}$ as a function of temperature calculated by combining DSC and ICD data. This method can be applied to any unfolding transition provided that the thermal denaturation is reversible and that the unfolding process is the same over the whole temperature interval. 


\subsection{Case 2: The Structural Stability of Proteins that Exhibit Irreversible}

Thermal Denaturation. The thermal denaturation of HEW lysozyme is reversible at low $\mathrm{pH}$ values but irreversible at neutral $\mathrm{pH}$ as shown in Figure $4 \mathrm{a}$, where the irreversibility is reflected by the lack of any transition in the repeated scan of the same sample. In addition, the exothermic drop in the heat capacity at the end of the scan corresponds to precipitation of the aggregated protein. At pH 7.5 HEW lysozyme denatures irreversibly with a midpoint temperature of $72.4^{\circ} \mathrm{C}$ and a $\Delta H^{\circ}$ of $112 \mathrm{kcal} / \mathrm{mol}$. Thermal unfolding of HEW lysozyme is reversible at $\mathrm{pH}$ values lower than 5.0 where thermodynamic data has been previously obtained by DSC $(2,16-19)$.

In contrast to thermal denaturation, the chemical denaturation of HEW lysozyme at $\mathrm{pH} 7.5$ is reversible as demonstrated by the overlapping denaturation and renaturation curves in Figure $4 \mathrm{~b}$. ICD experiments at $25^{\circ} \mathrm{C}$ yield a $\Delta G^{\circ}$ of 10.7 $\mathrm{kcal} / \mathrm{mol}$. A combination of DSC and ICD allows definition of the entire $\mathrm{pH}$ dependence of HEW lysozyme stability. Figure 5 shows $\Delta G^{\circ}$ at $25{ }^{\circ} \mathrm{C}$ as a function of $\mathrm{pH}$. The data at $\mathrm{pH} 2-4$ were obtained by DSC $(16,19)$. The data at $\mathrm{pH} 2\left(\Delta G^{\circ}=5.0 \mathrm{kcal} / \mathrm{mol}\right), 2.5$ and 4.0 were obtained by digitizing and analyzing figure 2 in ref (16). The $\Delta G^{\circ}$ value of $7.1 \mathrm{kcal} / \mathrm{mol}$ at $\mathrm{pH} 2.0$ was calculated from the enthalpy and $\Delta C_{p}$ determined by Pfeil and Privalov (19). The data from $\mathrm{pH} 4$ -7.5 were obtained by ICD. The experiments demonstrate that for the $\mathrm{pH}$ region in which data can be obtained by both DSC and ICD, the $\Delta G^{\circ}$ values coincide. ICD allows continuation of the curve to those regions in which temperature 
denaturation becomes irreversible. The combination of DSC and ICD allows determination of the complete $\mathrm{pH}$ dependence of $\Delta G^{\circ}$ at $25^{\circ} \mathrm{C}$ or other low temperatures.

3.3 Case 3: DSC and ICD on Extremely Stable Proteins. Some proteins, especially those from hyper-thermophilic organisms undergo thermal denaturation at temperatures above the operating range of DSC instruments. Also, for some highly stable proteins complete denaturation cannot be achieved by urea or $\mathrm{GdnHCl}$ alone. In those situations a plausible alternative is to perform experiments with one denaturant in the presence of various constant amounts of a second denaturant. An example is $\mathrm{GdnHCl}$ denaturation in the presence of different concentrations of urea. In this case, $\Delta G$ is described by the following equation:

$\Delta G=\left(\Delta G^{o}-m_{\text {urea }}[\right.$ Urea $\left.]\right)-m_{G d n H C l}[G d n H C l]$

We tested the validity of the approach with HEW lysozyme, which at $\mathrm{pH} 7.5$ is in the determination limit of $\mathrm{GdnHCl}$ when used alone. $\mathrm{GdnHCl}$ experiments were performed in the presence of 1,2 , and $3 \mathrm{M}$ urea concentrations. The experiments were performed in triplicate and are shown in Figure 6. The three sets of experiments were analyzed globally in order to solve Eq. 2 for $\Delta G^{\circ}, m_{\text {urea }}$ and $m_{\text {GdnHCl. }}$ Figure 7 shows the results from the global fit. The resulting values 
for $\Delta G^{\circ}$ and $m_{G d n H C l}$ for lysozyme in the absence of any urea are $10.7 \pm 0.4$ $\mathrm{kcal} / \mathrm{mol}$ and $3.0 \pm 0.1 \mathrm{kcal} /(\mathrm{mol} \times \mathrm{M})$, respectively. The value for $m_{\text {urea }}$ is $1.6 \pm$ $0.1 \mathrm{kcal} /(\mathrm{mol} \times \mathrm{M})$. The values are in agreement with the ones obtained with $\mathrm{GdnHCl}$ alone and with previously reported values $(20,21)$.

A thermostable protein that experiences irreversible denaturation is thermolysin which undergoes thermal denaturation at around $90{ }^{\circ} \mathrm{C}$ at $\mathrm{pH} 7.5(22)$. In this case, either urea or $\mathrm{GdnHCl}$ by themselves are not able to achieve complete denaturation. As in the case of $\mathrm{HEW}$ lysozyme, $\mathrm{GdnHCl}$ in the presence of different constant concentrations of urea was used to determine $\Delta G^{\circ}, \mathrm{m}_{\text {urea }}$ and $\mathrm{m}_{\mathrm{GdnHCl}}$. Figure $8 \mathrm{a}$ shows the $\mathrm{GdnHCl}$ denaturation of thermolysin in the presence of $3 \mathrm{M}$ urea together with renaturation scans recorded 11, 24, and 48 hours after dilution into wells containing different concentrations of denaturant (see section 2.3 for details of the method). Figure $8 \mathbf{b}$ shows the $C 1 / 2$ values obtained from the renaturation curves as a function of time. The $\mathrm{C} 1 / 2$ value for the renaturation of thermolysin requires almost 48 hours after dilution of the denatured protein before the $\mathrm{C} 1 / 2$ value for the renaturation scan coincides with that obtained in the denaturation experiment.

Complete datasets for the structural stability of thermolysin were obtained from $\mathrm{GdnHCl}$ denaturation experiments performed in the presence of $2.5,3$, and $3.5 \mathrm{M}$ urea concentrations. The denaturation curves are shown in Figure 9 . Figure 10 shows a global fit of the fraction of denatured thermolysin as a function of the 
concentrations of $\mathrm{GdnHCl}$ and urea. The value for $\Delta G^{\circ}$ obtained from global non-linear least squares analysis are $17.4 \pm 0.8 \mathrm{kcal} / \mathrm{mol}$ and the values for $m_{\text {GdnHCl }}$ and $m_{\text {urea }}$ are $3.4 \pm 0.2$ and $2.6 \pm 0.3 \mathrm{kcal} /(\mathrm{mol} \times \mathrm{M})$, respectively. As expected, the stability of thermolysin at room temperature is extremely high, around 80,000 -fold higher than HEW lysozyme at neutral $\mathrm{pH}\left(K^{\text {thermolysin }} / K^{\text {lysozyme }}\right.$ $=\mathrm{e}^{\left(-\Delta \Delta G^{\circ} / R T\right)}$.

\section{CONCLUSIONS}

There are situations, like the three considered in this paper, when stability data obtained by DSC can benefit from data obtained by ICD. The integration of two orthogonal techniques capable of measuring $\Delta G^{\circ}$ provides a more robust and complete thermodynamic characterization of protein stability, especially in those situations in which a single technique can only provide incomplete data. 


\section{REFERENCES}

1. Brandts, J. F., Oliveira, R. J., and Westort, C. (1970) Thermodynamics of protein denaturation. Effect of pressure on the denaturation of ribonuclease A, Biochemistry 9, 1038-1047.

2. Privalov, G., Kavina, V., Freire, E., and Privalov, P. L. (1995) Precise scanning calorimeter for studying thermal properties of biological macromolecules in dilute solution, Anal Biochem 232, 79-85.

3. Privalov, P. L., and Khechinashvili, N. N. (1974) A thermodynamic approach to the problem of stabilization of globular protein structure: a calorimetric study, J Mol Biol 86, 665-684.

4. Freire, E., and Biltonen, R. L. (1978) Statistical mechanical deconvolution of thermal transitions in macromolecules. I. Theory and application to homogeneous systems, Biopolymers 17, 463-479.

5. Privalov, P. L., Khechinashvili, N. N., and Atanasov, B. P. (1971) Thermodynamic analysis of thermal transitions in globular proteins. I. Calorimetric study of chymotrypsinogen, ribonuclease and myoglobin, Biopolymers 10, 1865-1890.

6. Tanford, C. (1968) Protein denaturation, Adv Protein Chem 23, 121-282.

7. Brower, E. T., Schon, A., and Freire, E. (2010) Naturally occurring variability in the envelope glycoprotein of HIV-1 and development of cell entry inhibitors, Biochemistry 49, 2359-2367. 
8. Pace, C. N. (1986) Determination and analysis of urea and guanidine hydrochloride denaturation curves, Methods Enzymol 131, 266-280.

9. Leavitt, S. A., SchOn, A., Klein, J. C., Manjappara, U., Chaiken, I. M., and Freire, E. (2004) Interactions of HIV-1 proteins gp120 and Nef with cellular partners define a novel allosteric paradigm, Curr Protein Pept Sci 5, 1-8.

10. Casares, S., Ab, E., Eshuis, H., Lopez-Mayorga, O., van Nuland, N. A., and Conejero-Lara, F. (2007) The high-resolution NMR structure of the R21A Spc-SH3:P41 complex: understanding the determinants of binding affinity by comparison with Abl-SH3, BMC Struct Biol 7, 22.

11. Martinez, J. C., Pisabarro, M. T., and Serrano, L. (1998) Obligatory steps in protein folding and the conformational diversity of the transition state, Nat Struct Biol 5, 721-729.

12. Medved, L. V., Migliorini, M., Mikhailenko, I., Barrientos, L. G., Llinas, M., and Strickland, D. K. (1999) Domain organization of the 39-kDa receptorassociated protein, J Biol Chem 274, 717-727.

13. Myers, J. K., Pace, C. N., and Scholtz, J. M. (1995) Denaturant $m$ values and heat capacity changes: relation to changes in accessible surface areas of protein unfolding, Protein Sci 4, 2138-2148.

14. Freire, E. (1995) Differential scanning calorimetry, Methods Mol Biol 40, $191-218$.

15. Robertson, A. D., and Murphy, K. P. (1997) Protein Structure and the Energetics of Protein Stability, Chem Rev 97, 1251-1268. 
16. Khechinashvili, N. N., Privalov, P. L., and Tiktopulo, E. I. (1973) Calorimetric investigation of lysozyme thermal denaturation, FEBS Lett 30, 57-60.

17. Pfeil, W., and Privalov, P. L. (1976) Thermodynamic investigations of proteins. II. Calorimetric study of lysozyme denaturation by guanidine hydrochloride, Biophys Chem 4, 33-40.

18. Pfeil, W., and Privalov, P. L. (1976) Thermodynamic investigations of proteins. III. Thermodynamic description of lysozyme, Biophys Chem 4, 41-50.

19. Pfeil, W., and Privalov, P. L. (1976) Thermodynamic investigations of proteins. I. Standard functions for proteins with lysozyme as an example, Biophys Chem 4, 23-32.

20. Ahmad, F., and Bigelow, C. C. (1982) Estimation of the free energy of stabilization of ribonuclease A, lysozyme, alpha-lactalbumin, and myoglobin, J Biol Chem 257, 12935-12938.

21. Ahmad, F., Yadav, S., and Taneja, S. (1992) Determining stability of proteins from guanidinium chloride transition curves, Biochem J 287 ( $P t$ 2), 481-485.

22. Sanchez-Ruiz, J. M., Lopez-Lacomba, J. L., Cortijo, M., and Mateo, P. L. (1988) Differential scanning calorimetry of the irreversible thermal denaturation of thermolysin, Biochemistry 27, 1648-1652. 


\section{FIGURE LEGENDS}

Figure 1. The temperature dependence of the heat capacity function of gp120. The dashed lines are linear extrapolations of the baselines that correspond to the native and denatured states of gp120. This behavior is often seen in DSC of proteins and precludes accurate determination of $\Delta \mathrm{C}_{\mathrm{p}}$.

Figure 2. The fraction of denatured gp120 obtained as a function of urea concentration for three different protein samples in PBS, $\mathrm{pH} 7.5$, at $25^{\circ} \mathrm{C}$. The protein concentration was $\sim 30 \mu \mathrm{g} / \mathrm{mL}$. Analysis of the data yields $\Delta \mathrm{G}=7.30 \pm$ $0.08 \mathrm{kcal} / \mathrm{mol}, \mathrm{m}=2.70 \pm 0.05 \mathrm{kcal} /(\mathrm{mol} \times \mathrm{M})$, and $\mathrm{C} 1 / 2=2.71 \pm 0.03 \mathrm{M}$.

Figure 3. The temperature dependence of the Gibbs energy of stability for gp120 and its enthalpic and entropic components. The values were calculated by combining data from DSC and ICD.

Figure 4. (a) The temperature dependence of the heat capacity function of HEW lysozyme at $\mathrm{pH}$ 7.5. The transition is irreversible as reflected by the lack of any transition in the repeated scan of the same sample. (b) Chemical denaturation and renaturation scans of lysozyme at $\mathrm{pH} 7.5$, using $\mathrm{GdnHCl}$ as denaturant. The overlapping curves demonstrate the reversibility of the chemical denaturation of lysozyme. Both ICD experiments in the figure were performed in the presence of a constant concentration of $2 \mathrm{M}$ urea (see method section 2.3 for details). 
Figure 5. Gibbs energy of stability for lysozyme as a function of $\mathrm{pH}$. The values in the region $\mathrm{pH} 4-7.5$ indicated by the filled circles were determined by ICD. The values indicated by the filled squares below $\mathrm{pH} 4.0$, where thermal denaturation of lysozyme is reversible, were calculated from values for $\Delta H^{\circ}$ and $\Delta \mathrm{C}_{\mathrm{p}}$ determined by $\mathrm{DSC}$ in refs $(16,19)$ (see text for details).

Figure 6. $\mathrm{GdnHCl}$ denaturation of lysozyme at $\mathrm{pH} 7.5$ in the presence of $1(\boldsymbol{\square})$, $2(\mathbf{\Delta})$, and $3 \mathrm{M}(\bullet)$ urea. The protein concentration was $\sim 30 \mu \mathrm{g} / \mathrm{mL}$.

Figure 7. Global fit of the fraction denatured lysozyme as a function of the concentration of $\mathrm{GdnHCl}$ and urea in phosphate buffer, $\mathrm{pH}$ 7.5. The global fit is used to determine simultaneously $\Delta G^{\circ}, m_{G d n H C l}$ and $m_{\text {urea }}$ by non-linear least squares.

Figure 8. Chemical denaturation and renaturation scans of thermolysin using $\mathrm{GdnHCl}$ as denaturant at $\mathrm{pH}$ 7.5, $\left(10 \mathrm{mM}\right.$ hepes, $\left.100 \mathrm{mM} \mathrm{NaCl}, 10 \mathrm{mM} \mathrm{CaCl}_{2}\right)$ in the presence of a constant concentration of $3 \mathrm{M}$ urea. The renaturation scans were recorded $11,16,24$, and 48 hours times after the protein in high denaturant was diluted into wells containing buffer with different concentrations of denaturant. (For ease of viewing, the curve obtained after 16 hours has not been included in the figure.) b) $\mathrm{C} 1 / 2$ obtained from the renaturation scans recorded $11,16,24$, and 48 hours after dilution of the denatured protein. The $C 1 / 2$ value obtained from the denaturation scan has been added for comparison (48 h). 
Figure 9. The fraction denatured thermolysin as a function of the concentration of $\mathrm{GdnHCl}$ in the presence of different urea concentrations: $2.5(\mathbf{\square}), 3(\mathbf{\Delta})$, and 3.5 $\mathrm{M}(\bullet)$. The conditions are the same as described in the legend to Figure 8 .

Figure 10. Global fit of the fraction of denatured thermolysin as a function of the concentration of $\mathrm{GdnHCl}$ and urea. As in Figure 7, the global fit allowed simultaneous determination of $\Delta G^{\circ}, m_{G d n H C l}$ and $m_{\text {urea. }}$ 
Figure 1

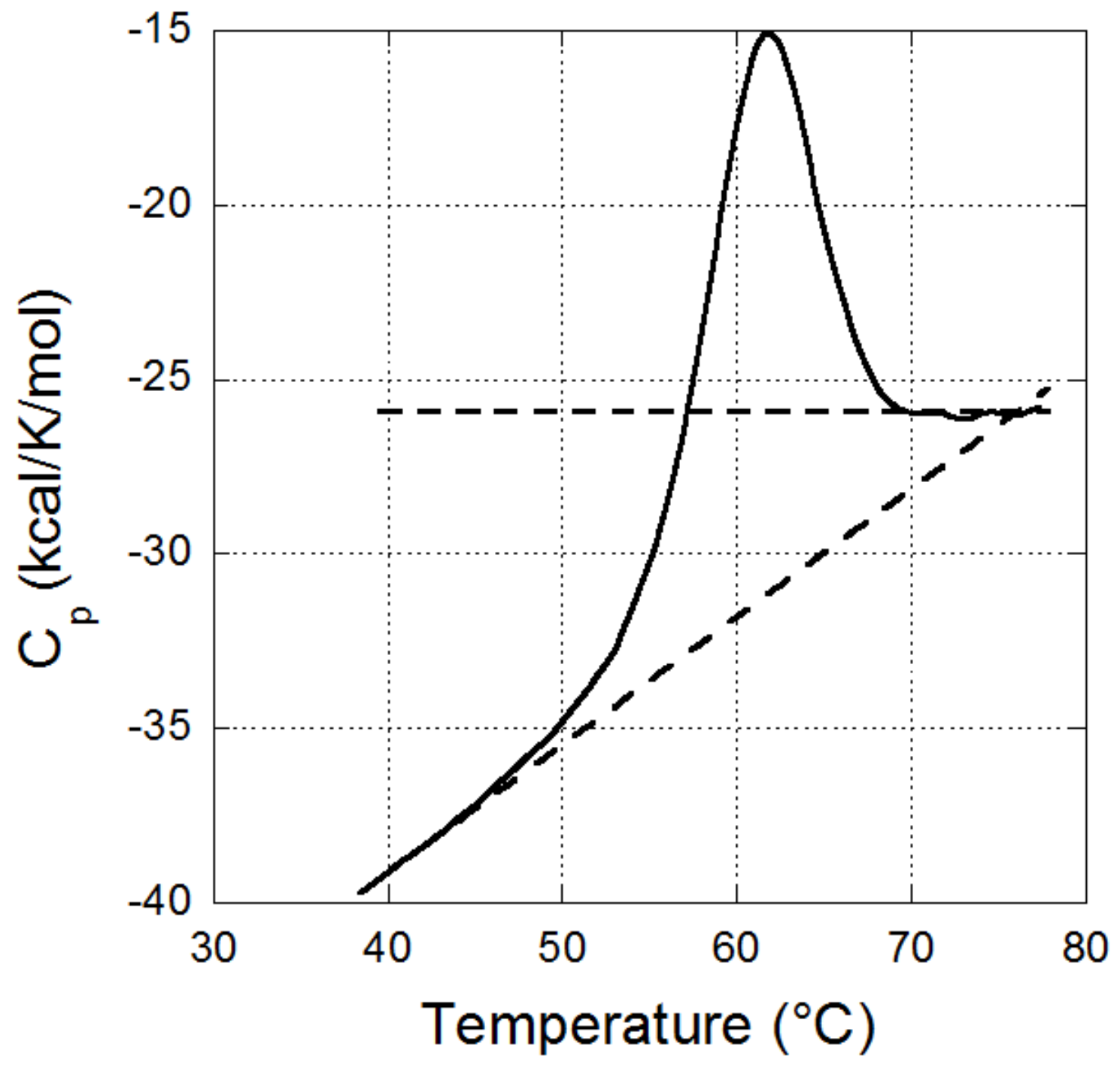


Figure 2

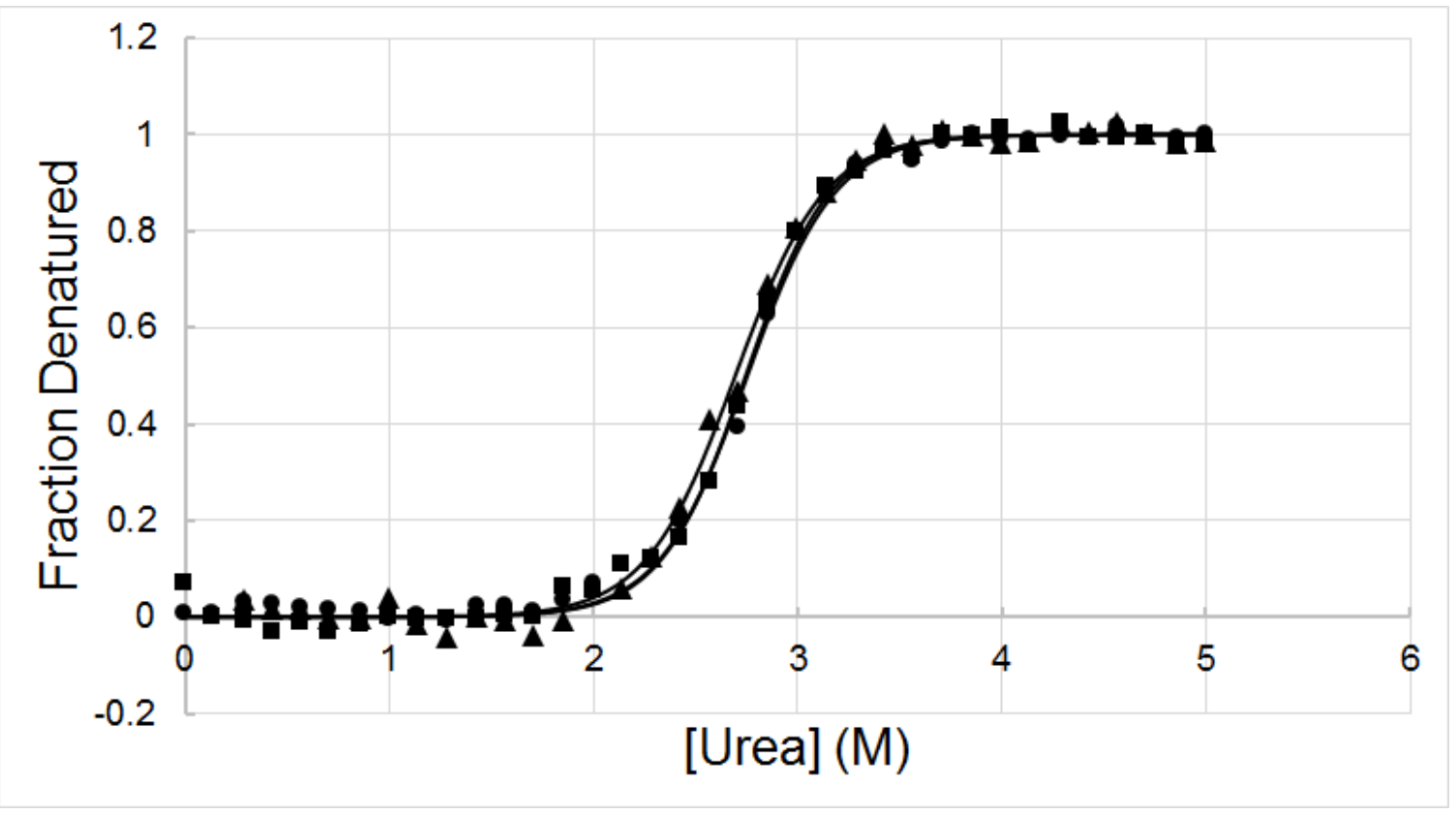


Figure 3

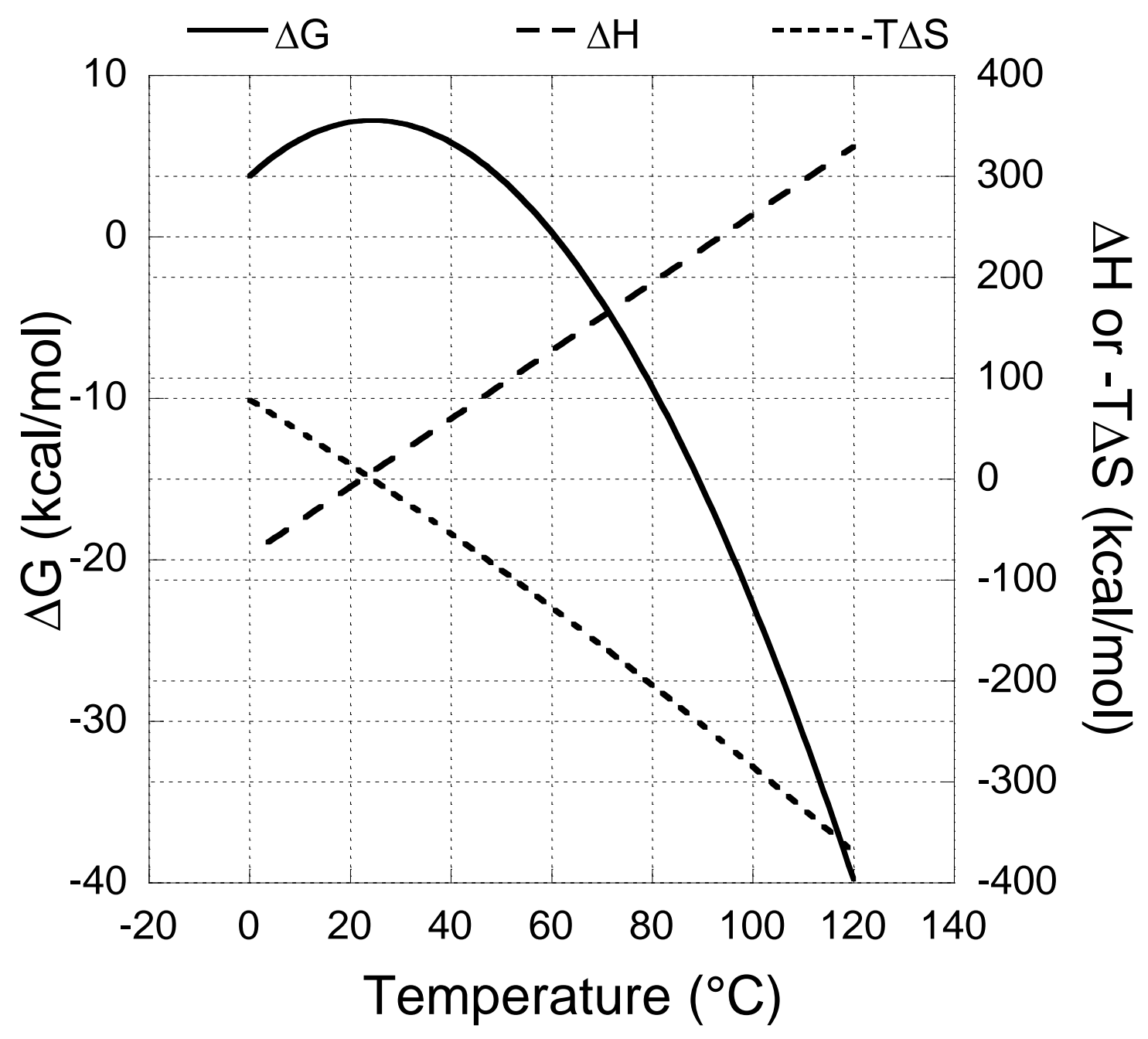


Figure 4
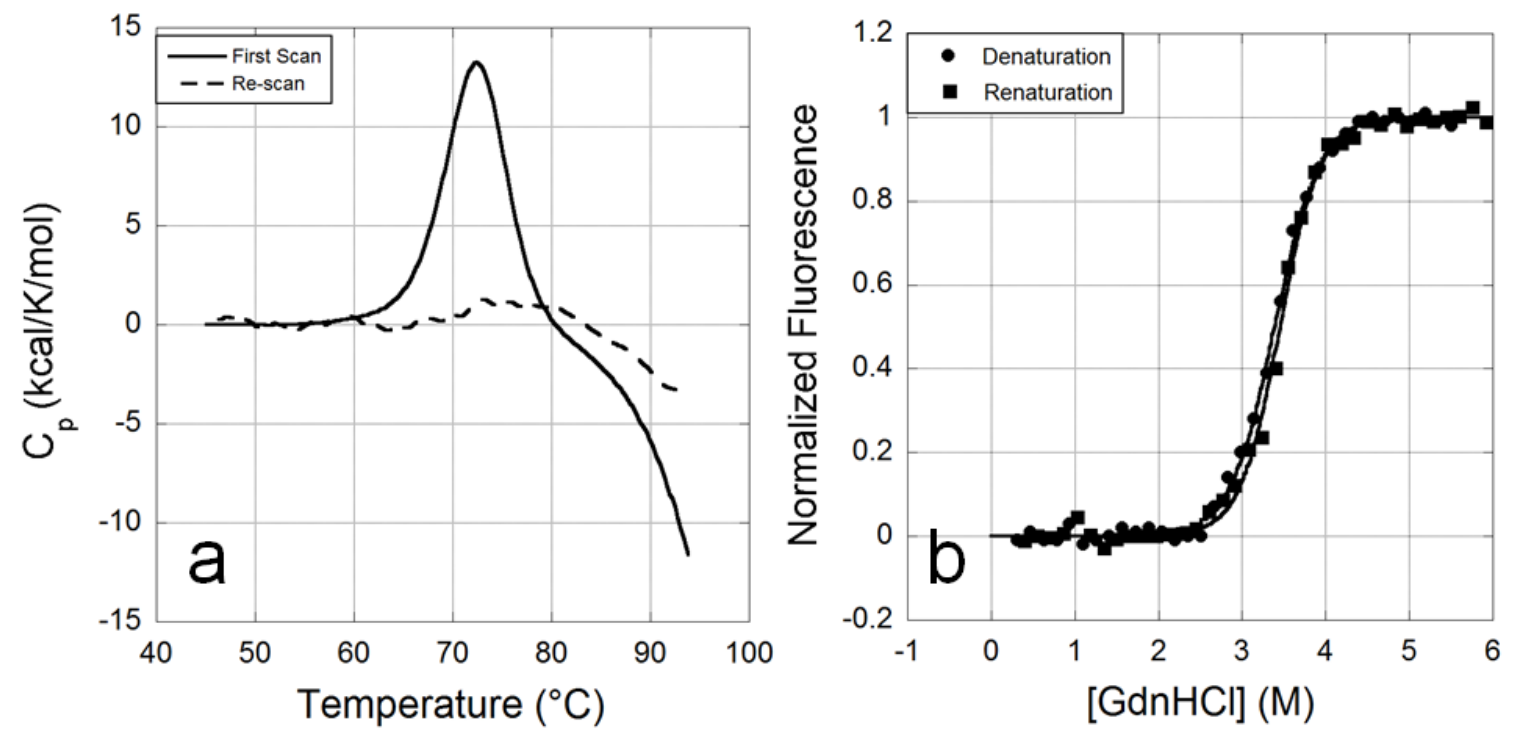
Figure 5

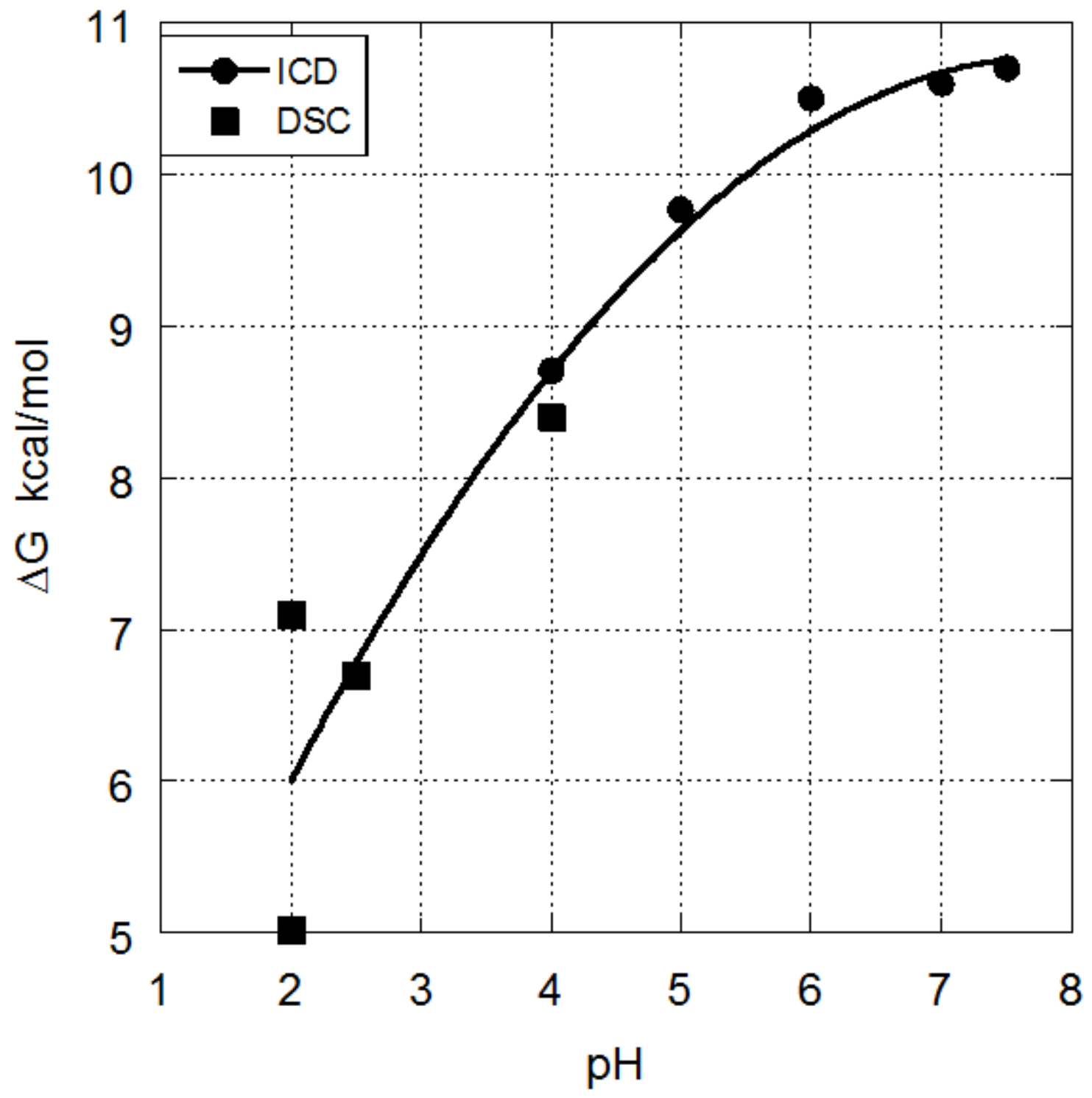


Figure 6

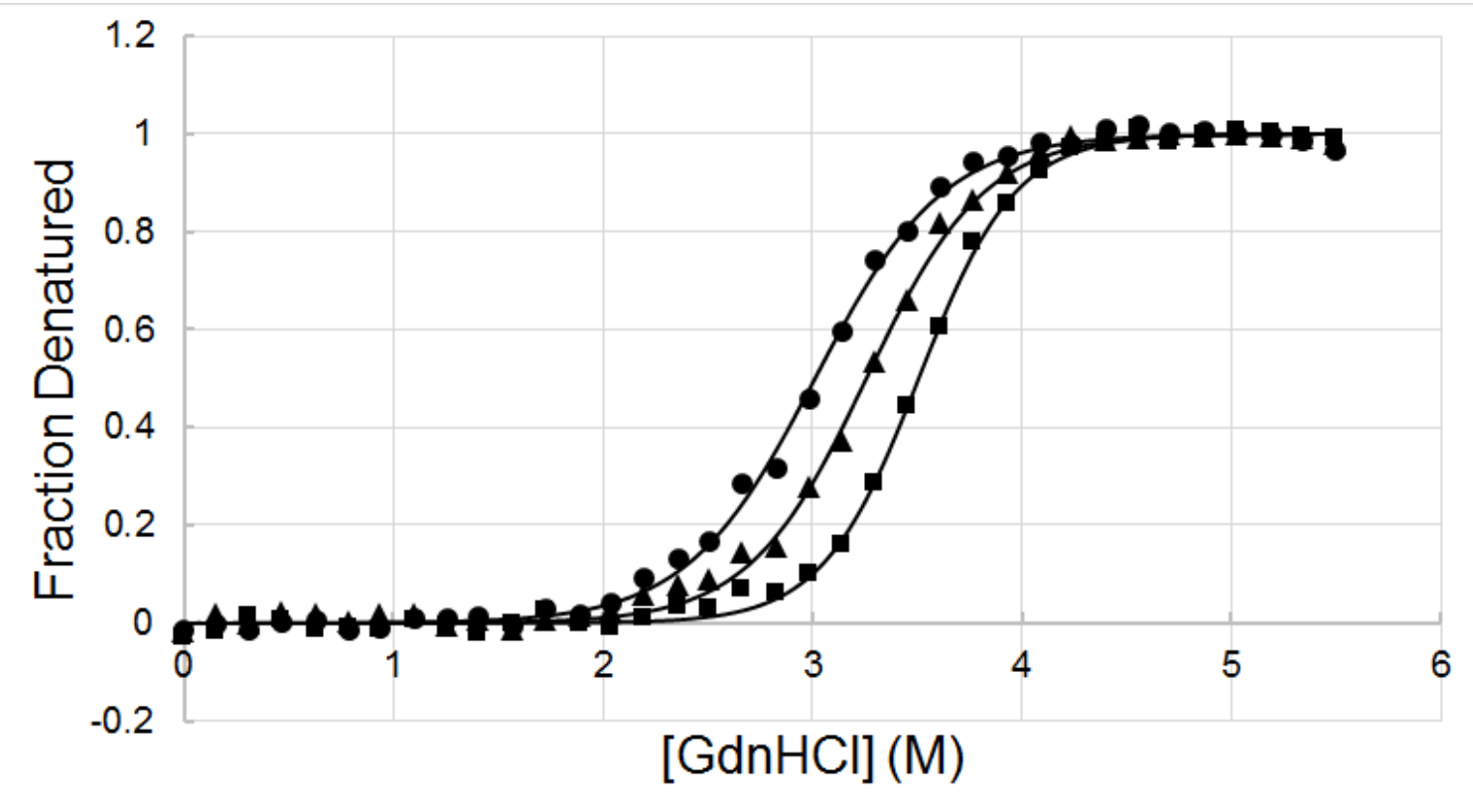


Figure 7

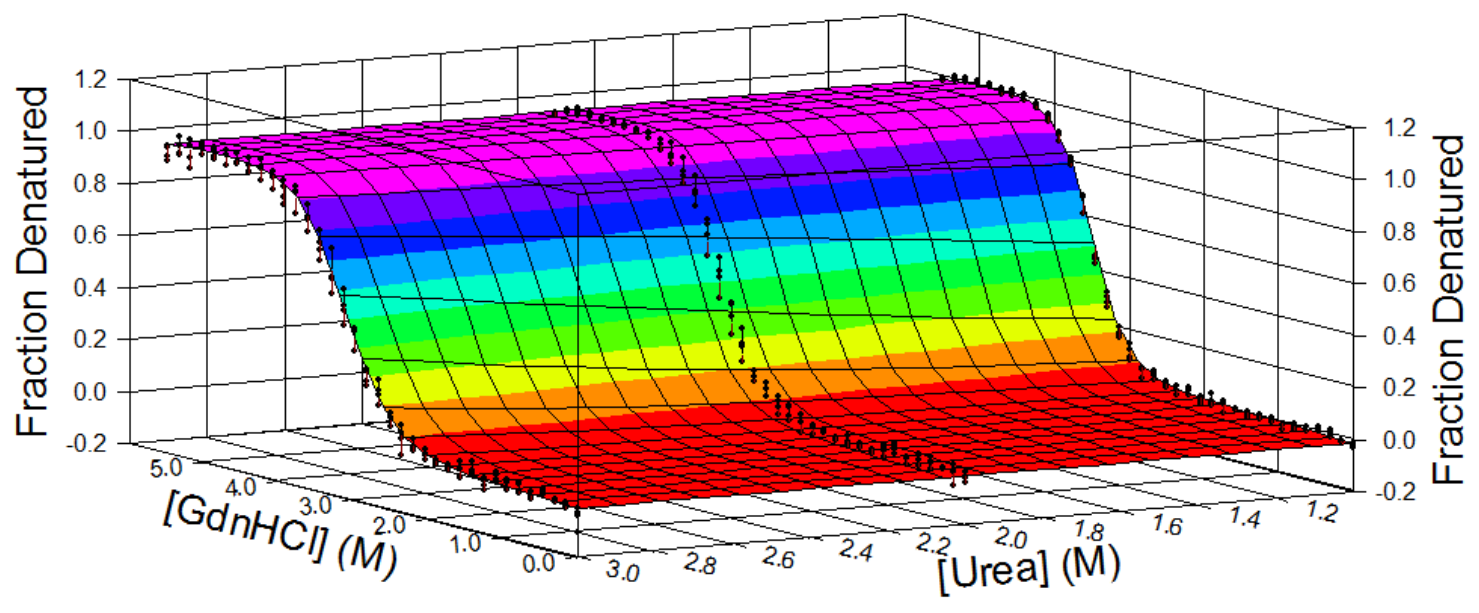


Figure 8
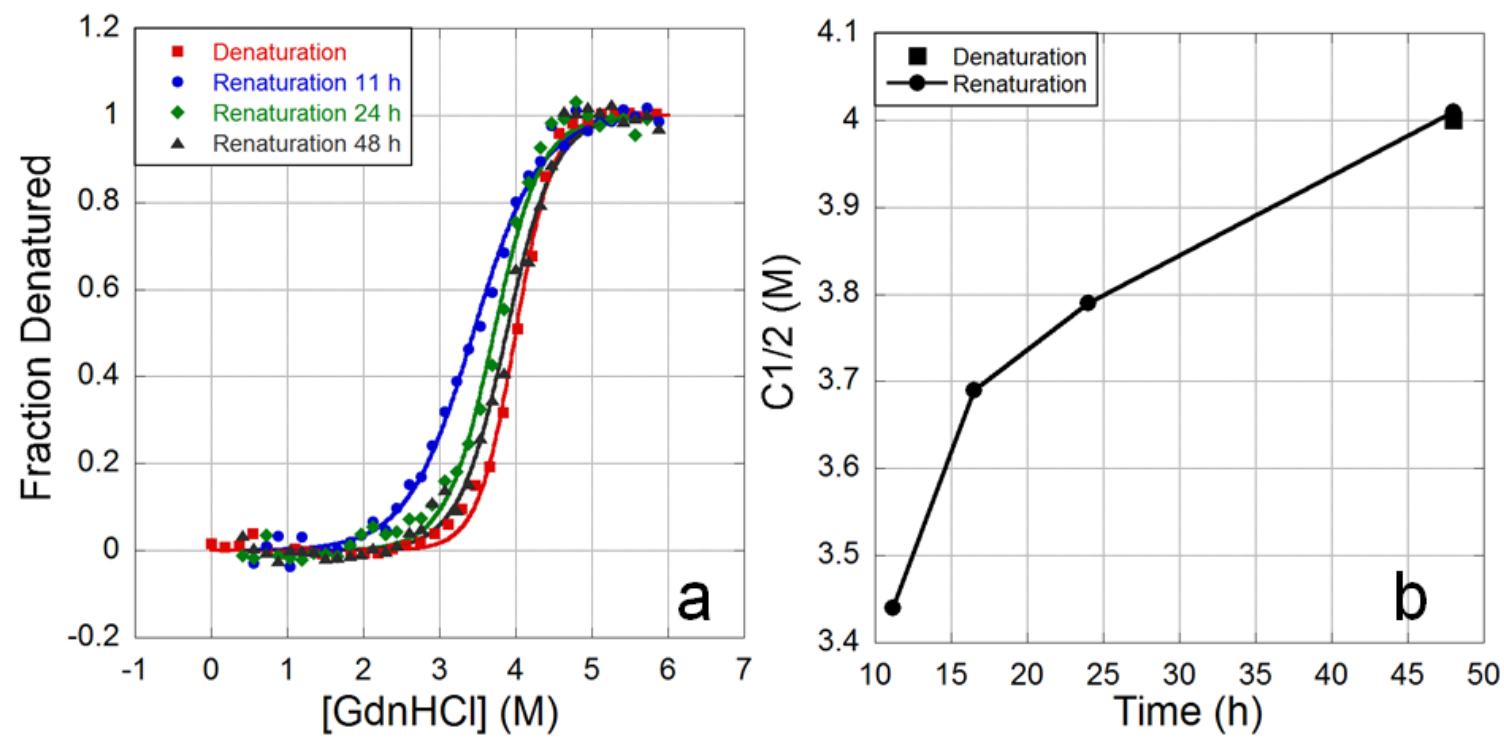
Figure 9

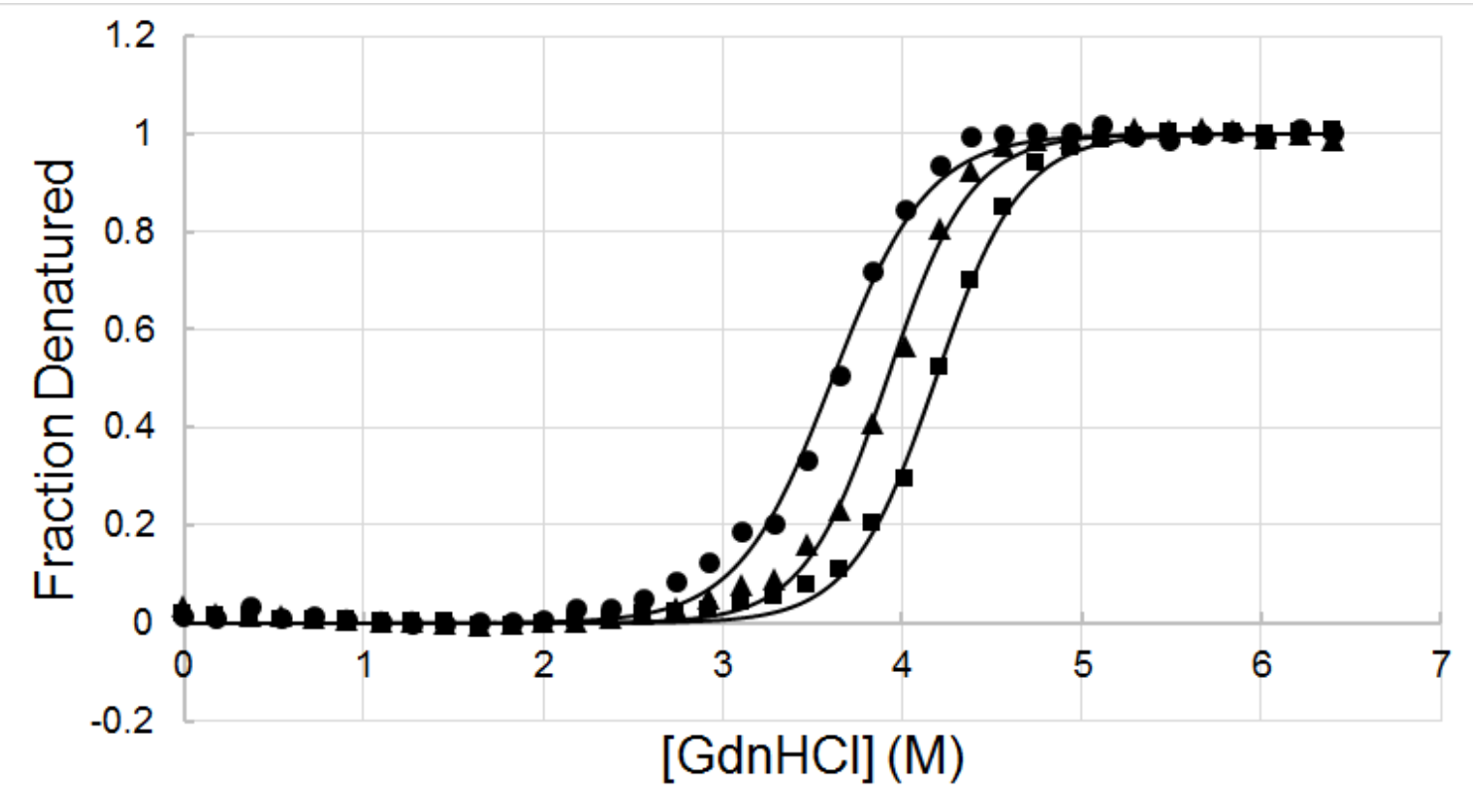


Figure 10

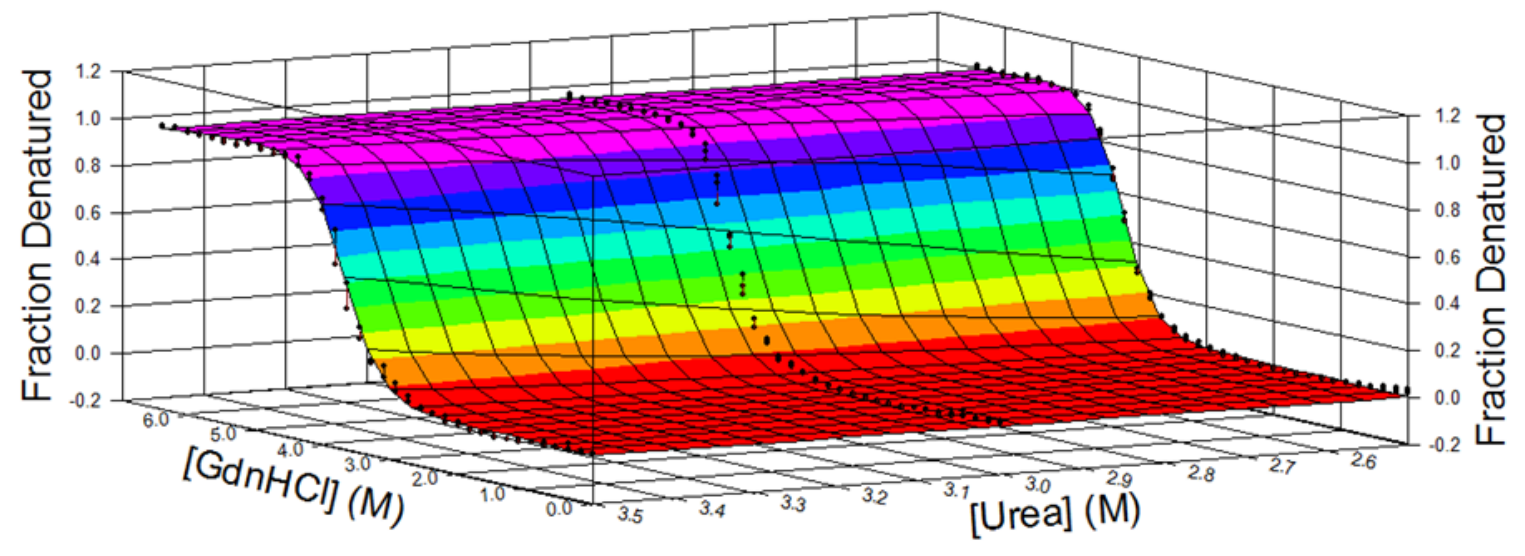

